\title{
Computer-based learning of spelling skills in children with and without dyslexia
}

\section{Journal Article}

\section{Author(s):}

Kast, Monika; Baschera, Gian-Marco; Gross, Markus; Jäncke, Lutz; Meyer, Martin

Publication date:

2011-12

Permanent link:

https://doi.org/10.3929/ethz-b-000413259

Rights / license:

In Copyright - Non-Commercial Use Permitted

Originally published in:

Annals of Dyslexia 61(2), https://doi.org/10.1007/s11881-011-0052-2 


\title{
Computer-based learning of spelling skills in children with and without dyslexia
}

\author{
Monika Kast • Gian-Marco Baschera • Markus Gross • \\ Lutz Jäncke • Martin Meyer
}

Received: 1 June 2010 / Accepted: 8 February 2011 /Published online: 12 May 2011

(C) The International Dyslexia Association 2011

\begin{abstract}
Our spelling training software recodes words into multisensory representations comprising visual and auditory codes. These codes represent information about letters and syllables of a word. An enhanced version, developed for this study, contains an additional phonological code and an improved word selection controller relying on a phoneme-based student model. We investigated the spelling behavior of children by means of learning curves based on log-file data of the previous and the enhanced software version. First, we compared the learning progress of children with dyslexia working either with the previous software $(n=28)$ or the adapted version $(n=37)$. Second, we investigated the spelling behavior of children with dyslexia $(n=37)$ and matched children without dyslexia $(n=25)$. To gain deeper insight into which factors are relevant for acquiring spelling skills, we analyzed the influence of cognitive abilities, such as attention functions and verbal memory skills, on the learning behavior. All investigations of the learning process are based on learning curve analyses of the collected log-file data. The results evidenced that those children with dyslexia benefit significantly from the additional phonological cue and the corresponding phoneme-based student model. Actually, children with dyslexia improve their spelling skills to the same extent as children without dyslexia and were able to memorize phoneme to grapheme correspondence when given the correct support and adequate training. In addition, children with low attention functions benefit from the structured learning environment. Generally, our data showed that memory sources are
\end{abstract}

The authors Monika Kast and Gian-Marco Baschera contributed equally to the manuscript.

M. Kast $\cdot$ L. Jäncke $\cdot$ M. Meyer

Department of Neuropsychology, University of Zurich, Zurich, Switzerland

G.-M. Baschera $(\bowtie) \cdot$ M. Gross

Institute for Computational Science, ETH Zürich, Haldeneggsteig 4/Weinbergstrasse, 8092 Zurich, Switzerland

e-mail: gianba@inf.ethz.ch

M. Kast $(\bowtie)$

Institute of Neuropsychology, University of Zurich, Binzmühlestrasse 14/25, 8050 Zurich, Switzerland e-mail: monika.kast@inf.ethz.ch 
supportive cognitive functions for acquiring spelling skills and for using the information cues of a multi-modal learning environment.

Keywords Acquiring spelling skills · Associative learning · Developmental dyslexia · Learning curves $\cdot$ Multisensory learning

\section{Introduction}

The phonological deficit in developmental dyslexia

Spelling and reading skills are essential in modern societies where information is commonly provided by written media. In the case of developmental dyslexia (DD), the acquisition of these cultural techniques is impaired. Individuals affected by DD are characterized by low spelling and writing skills in spite of having an average IQ, good educational support, and a solid social background (World Health Organization, 1993). Thus, DD is a learning disability with a specific language-based disorder of constitutional origins. The difficulties are manifested in reading difficulties and as a conspicuous problem with acquiring proficiency in writing and spelling (Lyon, Shaywitz, \& Shaywitz 2003).

The causes of spelling and reading failure are still debated. There are several theories focusing on the various impairments suffered by individuals with dyslexia, namely, general auditory (Baldeweg, Richardson, Watkins, Foale, \& Gruzelier 1999; Farmer \& Klein, 1995; Reed, 1989; Tallal, 1980), visual (Livingstone \& Hubel, 1988; Lovegrove, Bowling, Badcock, \& Blackwood 1980; Stein \& Walsh, 1997) or motor impairments (Nicolson \& Fawcett, 1990; Rudel, 1985; Wolff, Michel, \& Ovrut 1990). The most accepted theory, however, is the phonological processing deficit hypothesis (Bradley \& Bryant, 1983; Ramus, Rosen, Dakin, Day, Castellote, White, \& Frith 2003). This theory claims poor phonological awareness that manifests as impairment in the phoneme to grapheme conversion (Frith, 1985).

Early readers have to learn to pair printed letters of the alphabet (i.e., graphemes) with verbally represented sounds (i.e., phonemes) (Adams, 1990; Snowling, Bishop, \& Stothard 2000). The acquisition of this culturally defined grapheme-phoneme knowledge is a critical and fundamental skill for learning to read and spell (Byrne, 1998; Muter, Hulme, Snowling, $\&$ Stevenson 2004). Extended practice of grapheme-phoneme learning leads to improved word recognition (Li, Shu, McBride-Chang, Liu, \& Xue 2009). Thus, reading skills have been linked with paired associative learning, i.e., the ability to associate a verbal and visual stimulus with each other (Hulme, Goetz, Gooch, Adams, \& Snowling 2007).

In literate adults, the phoneme to grapheme mapping occurs rapidly and automatically (Paulesu et al., 1996) and can be considered an over-learned paired association process (van Atteveldt, Formisano, Goebel, \& Blomert 2007). However, individuals with dyslexia often have extreme difficulties in learning the letter-sound correspondence, and a high level of these culturally defined associations may never be reached (Vellutino, Fletcher, Snowling, \& Scanlon 2004). Additionally, individuals with dyslexia show difficulties in learning the association between an abstract form and nonsense syllables (Gascon \& Goodglass, 1970; Vellutino, Steger, Harding, \& Phillips 1975). On the contrary, individuals with dyslexia performed normally on nonverbal paired association tasks such as learning to associate one abstract shape with another (Goyen \& Lyle, 1971; Vellutino et al., 1975). These problems in visual-verbal association tasks and the lack thereof in visual-visual mapping tasks were found in both Chinese and Western children with dyslexia (Li et al., 2009; Messbauer \& de 
Jong, 2003). Messbauer and de Jong (2003) argued that the difficulty with visual-verbal association tasks, involving words and nonwords, did not reflect problems in the acquisition of new phonological representations, but was instead more likely to represent a general phonological learning difficulty.

The aforementioned phonological learning difficulties are linked with a reduced phonicsbased memory as exhibited by individuals with dyslexia. Therefore, reduced working memory may cause problems in maintaining phonological information in a particular sequence (Goswami, Ziegler, \& Richardson 2005). It has been suggested that children with dyslexia compared with children without dyslexia use different memory strategies. While children with dyslexia rely on a nonphonological, visual coding strategy for the mediation of the written words in working memory, children without dyslexia use phonological coding (Miller \& Kupfermann, 2009).

\section{Multisensory learning}

Studies pertaining to learning, as well as investigations of memory, have predominantly focused on learning stimuli consisting of a single sensory modality or on unisensory memories. In recent years, it has been suggested that, in natural environments, information is mostly integrated across multiple sensory modalities (Shams \& Seitz, 2008). Thus, the human brain has evolved to develop, learn, and operate optimally in multisensory environments. There is evidence that multisensory training, as opposed to unisensory training, promotes more effective learning of information. Additionally, it is assumed that multisensory experiences enrich our memories and influence ongoing processes (Shams \& Seitz, 2008). Indeed, how the brain codes rich sensory aspects of a memory during the process of retrieval is still a fundamental question.

Neuronal models predict that brain areas active during sensory-induced perceptions are reactivated during the retrieval of such information. Data obtained by a positron emission tomography (PET) and a functional magnetic resonance imaging (fMRI) study provide evidence that retrieval of visual information, which had previously been paired with auditory stimuli over an extensive training period, activated both visual and auditory brain areas (Nyberg, Habib, McIntosh, \& Tulving 2000; Wheeler, Petersen, \& Buckner 2000). Also, behavioral data indicate that multisensory encoded experiences enhance perception and facilitate the retrieval of memory (Lehmann \& Murray, 2005). This occurs even if the stimuli were only unimodally presented in the retrieval condition. Associations between meaningful auditory information and visual codes were more accurately responded to in the retrieval session, than only visually learned stimuli (Lehmann \& Murray, 2005).

\section{Computer-assisted learning}

The benefits of multisensory learning and the indication that children with dyslexia use a nonphonological, visual coding strategy were integrated in the production of new computer-based training programs. The advantages of computer games are that they have both recreational and didactic goals (Crespo Garcia, Delgado Kloos, \& Castro Gil 2008). Successful educational games are aiming to capture student's interest, thereby, motivating them to acquire knowledge.

A multi-modal training program based on the approach of associative learning was presented by a Finnish group (Kujala et al., 2001). They were able to show that reading improved strongly after an association learning of abstract audio-visual material. Their computer-based training of basal components of reading and writing incorporates nonverbal 
tasks that require audio-visual matching of rhythm, pitch, and intensity. As a result, the trainee's multi-modal coding of speech stimuli improves, which consequently enhances reading and writing capabilities in 7-year-old children (Kujala et al., 2001).

Other training programs focus on the core phonological processing deficit. Ecalle, Magnan, Bouchafa, \& Gombert (2009) present a learning software package that includes audio-visual phoneme discrimination tasks. In their training tasks, orthographic units have to be discriminated based on simultaneously presented phonological units. This helps to improve both reading and spelling skills in children with dyslexia (Ecalle et al., 2009). An additional multimedia program was developed for children, in order to help them build up a relatively stable phonologically underpinned orthographic representation, particularly for learning words with irregular phoneme-grapheme correspondence in Dutch (Hilte \& Reitsma, 2006). The findings of this study indicate that practice with spelling pronunciations is as beneficial as practice with visual preview, and it is significantly more effective than practice with normal pronunciation (Hilte \& Reitsma, 2006). The strong effect of the visual preview highlights the need for a prevention of misspelled words.

To increase the training efficacy of a spelling training, M. Bodén and M. Bodén (2007) proposed an evolutionary approach for adapting spelling exercises to suit individual student needs. Similar words are selected if an error has been committed by the user; however, the similarity measure does not consider the error type or position (M. Bodén \& M. Bodén, 2007).

\section{The spelling software (REF)}

The computer-based German spelling program examined in this study, namely, (REF), is based on the concepts of information theory and multi-modal learning (REF). The central idea of the training software involves recoding a sequential input string into a multi-modal representation by using a set of codes. The program relies on meaningful visual and auditory stimuli to support the spelling learning process. Previous findings of behavioral data indicate that meaning (e.g., environmental sounds compared with sine wave tones) is necessary to facilitate the retrieval of multisensory encoded information (Lehmann \& Murray, 2005). The visual cues implemented in the learning software use colors and shapes that reflect information about individual letters. The concept of associative learning used in our software is similar to the learning program examined by the Finnish group (Kujala et al., 2001). However, our visual and auditory stimuli contain additional information about accurate spelling.

Additionally, a topological code in the software that syllabifies the word is implemented to provide a clear structure. It supports the children in their serial behavior during spelling because it assists them with putting the letters in the right position. This is in line with the theoretical framework determining the cognitive architecture of spelling (Lashley, 1951). This theory relies on the notion that spelling is an endogenous generation of serial behavior. Therefore, letters are produced one at a time and must be produced in the correct order. The auditory code, which redundantly represents syllable and color information in rhythm and pitch respectively, completes the multi-modal set of codes illustrated in Fig. 1. The entire recoding can be applied to other alphabetic languages (REF).

The software used in the present study is structured into three different games. In the first game, that is, the color game, students have to learn the association between a letter and a color. Based on the information, theoretical model of the spelling program, eight different colors are used. The mapping of letters to colors is the result of a multi-objective optimization, taking into account that, e.g., letters easily confused by dyslexics, such as ' $t$ ' and ' $d$ ', map to different colors. In the second game, namely, the graph game, the students are required to segment a word into its syllables and letters graphically. The structure of the 


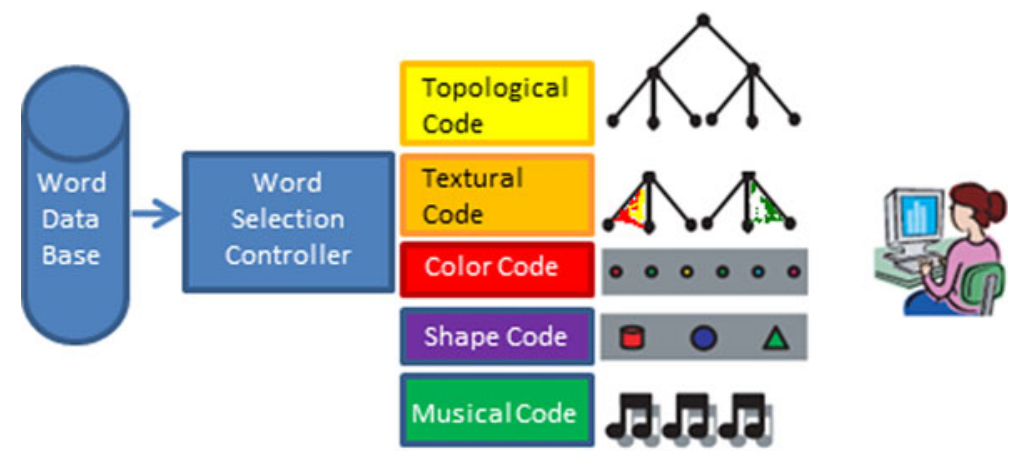

Fig. 1 The word selection controller was adapted for the second user study. The visual and auditory codes of the original software version represented letter and syllable information in color, shape, topological, and auditory cues. The information mediated by the visual system corresponds with the auditory information, i.e., color corresponds with tone and shape with instrument. For the second study, these cues where expanded with a textural code containing phonological information. Theoretical framework and conceptual components of the learning software's methods

word is visualized in a so-called syllable graph. This game provides an important training of segmenting words in syllables; this is a necessary component since there is evidence that the accurate perception of metrical structure in speech and music is critical for phonological development and, consequently, for the development of literacy (Huss, Verney, Fosker, Mead, \& Goswami 2010).

In the third game, the actual spelling game, the computer program presents all alternative representations of a word before the students enter the word themselves by using the keyboard. The game proceeds as follows: a graph appears on screen, and the colors and shapes (spheres for small letters, cylinders for capital letters, and pyramids for umlauts) are displayed for all letters, as shown in Fig. 2. Then, a female voice dictates a word, and the

Fig. 2 The two-syllable word 'Rückkehr' is visualized in the syllabic segmentation. Each syllable lasts $1 \mathrm{~s}$ and the duration of sounds is dependent on the number of letters belonging to one syllable. The correspondence of the graphemes 'ck' and 'eh' to the phonemes /k/ and /e:/, respectively, is visualized by the textured triangles between the letters. Illustration of the appearance of the components and framework on the screen

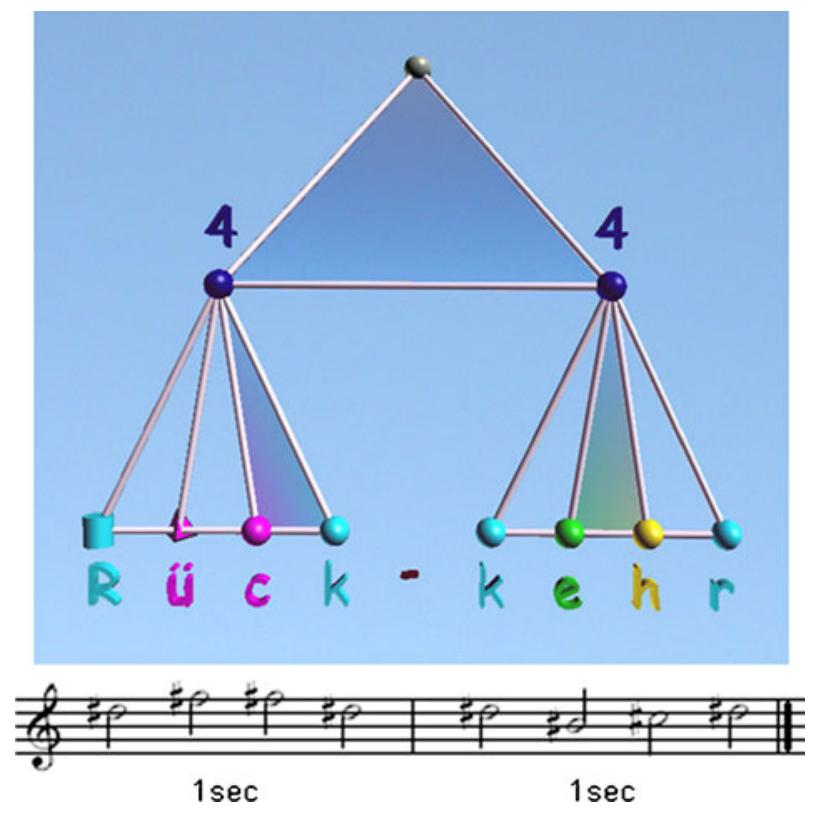


students hear the corresponding melody. While the student enters the word, the computerbased spelling program gives visual and auditory feedback in response to the spelling behavior. This leads to an instantaneous correction of committed errors and prevents the presentation of the erroneously spelled words.

The efficiency of our computer-based spelling program has been demonstrated in a previous study (REF). In the present study, we aimed to improve the program's effectiveness by adapting the learning program. Therefore, we expanded the framework of the learning software by employing two phoneme-based adjustments, which are based on the theory of phonological processing deficit. According to this theory, DD is manifested in reduced phonological awareness, which, in turn, leads to difficulties with learning the phoneme to grapheme conversion.

The first adaption to our version was the implementation of an additional textural code. This textural code visualizes the catenation of multiple letters to one grapheme that represents the corresponding phoneme (e.g., 'sch', 'ch', 'ie', 'ei', etc.). As can be seen in Fig. 2, the correspondence of the graphemes 'ck' and 'eh' to the phonemes /k/ and /e:/, respectively, is visualized by the textured triangles between the letters. This additional code supports the awareness of the phonological structure of the word.

The second adaption was the adjustment of the word selection controller. A novel phoneme-based student model (REF) was implemented in order to represent the specific spelling difficulties of individual children. In addition to the already used letter-based representation, which is able to handle typing errors and letter confusions, the student model incorporates phoneme-based mal-rules, such as, phoneme-grapheme matching (PGM) errors and auditory confusions. This student knowledge representation is continuously re-estimated, based on the error behavior of the present input data. Based on this information, the controller is able to adapt to the strengths and weaknesses of individual children. This enables the controller to expose each child to his or her own specific spelling problems. Hence, it permits a more detailed adaption to the student's skill set compared with M. Bodén and M. Bodén's evolutionary approach (2007).

Aim of the study

In the current study, we analyzed the learning progress based on the collected log-file data. First, we compared the log-file data from the first and the second study. This allowed for an evaluation of the adapted controller and the new phonological code implemented in the learning software. We expected children with dyslexia who worked with the revised software version to improve their spelling behavior significantly faster than individuals with dyslexia who worked with the original version.

Second, based on data collected in our second study, we investigated the influence of different cognitive factors on the learning progress. These factors included the indication of dyslexia, memory performances, and attention functions. Comparing children with and without dyslexia allowed us to explore whether both groups would benefit to the same extent from the training or if children with dyslexia, irrespective of the method used, would generally experience more problems acquiring spelling knowledge.

Our group decided to evaluate memory functions because it has been suggested that reading problems are associated with impaired memory functions (Schulte-Korne, Deimel, Bartling, \& Remschmidt 2004), which in turn cause reduced phonological representations. Attention functions build the general basis for learning as attention processes control all functions of our cognitive system, provided that tasks are not over-learned and automated (Zimmermann, Gondan, \& Fimm 2002). Attention helps people focus on the relevant 
information (Posner \& Presti, 1987). Therefore, we aimed to examine the influence of memory and attention functions on the spelling progress acquired in a structured environment.

\section{Methods}

Participants

Twenty-eight dyslexic children participated in the first study $\left(\mathrm{M}_{\mathrm{age}}=10.36 \pm 0.87 \mathrm{SD}\right.$ years of age, 18 females and ten males, 24 right-handed and four left-handed). Thirty-seven children with dyslexia $\left(\mathrm{M}_{\mathrm{age}}=10.89 \pm 0.94 \mathrm{SD}\right.$ years of age, ten females and 27 males, 30 right-handed and seven left-handed) and 25 children without dyslexia $\left(\mathrm{M}_{\mathrm{age}}=10.29 \pm 1.0 \mathrm{SD}\right.$ years of age, 12 females and 13 males, 23 right-handed and two left-handed) were recruited for the second study. The ages ranged from 8 to 12 years in both studies. Handedness was assessed by the "Hand-Dominanz-Test" (Steingruber, 1971) in the first study and by the (Annett, 1970) questionnaire in the second study. All children were native Swiss-German speakers with an IQ>85. Children with an IQ below 85 were excluded from the study. Notably, children with and without dyslexia attend public schools. All of the children's parents gave their informed consent for participation in the study as per the Declaration of Helsinki. Experimental procedures were approved by the local Ethics Committee (SPUK).

Children were categorized as dyslexic based on previous diagnosis by trained diagnosticians, such as, therapists or school psychologists. In order to further validate the diagnosis, children with dyslexia were categorized as reading- and spelling-disabled if their scores were below the tenth percentile on the standardized spelling and reading tests. In contrast, the reading and spelling skills of children without dyslexia were not more than 1 SD below $(\leq 15.9 \%)$ the mean. Children without dyslexia were recruited from responses to letters distributed in elementary schools or presentations in school classes where the program was demonstrated. The recruitment of children with dyslexia was conducted primarily with the assistance of therapists or educational psychology services.

\section{Test battery and procedure}

Before the training took place, an information event was organized for both children and their parents of the first and the second study in order to distribute detailed instructions about the study design and the concept of the learning software. Notably, the software is designed in a way that children can accomplish the training for themselves and do not need additional help or parental assistance. Detailed information about the handling of the learning software was presented on the first training day.

After providing general study information and before the actual training began, all study participants underwent a series of standard psychological tests (see, for results, Tables 1 and 2). The test battery for the participants in the first and second study differed slightly. In the first study, children performed the classical German spelling tests, "Salzburger-Lese und Rechtschreibtest SLRT" (Landerl, Wimmer, \& Moser 1997) or "Diagnostischer Rechtschreibtest für fünfte Klassen DRT5” (Grund, Haug, Naumann, \& Weinheim 1995). This enabled us to quantify their spelling skills. There were two different spelling tests applied because the SLRT contains only norms from the first to the fourth grade. Thus, the DRT5 was administered to the fifth graders. Additionally, all children were required to accomplish a standardized reading test, "Zürcher Lesetest ZLT" (Linder \& Grissemann, 
Table 1 Behavioral pre-test data for the children with dyslexia in study 1

\begin{tabular}{|c|c|c|c|c|}
\hline \multirow[b]{2}{*}{ Measures } & \multicolumn{4}{|c|}{ With dyslexia $(n=28)$} \\
\hline & Mean & $\mathrm{SD}$ & Min & Max \\
\hline Age (years) & 10.36 & 0.87 & 8.83 & 11.75 \\
\hline Grade level in school & 3.96 & 0.84 & 3.00 & 5.00 \\
\hline $\mathrm{IQ}^{\mathrm{a}}$ & 106.04 & 12.26 & 87.00 & 135.00 \\
\hline Verbal $\mathrm{IQ}^{\mathrm{a}}$ & 108.04 & 12.32 & 85.00 & 142.00 \\
\hline Performance $\mathrm{IQ}^{\mathrm{a}}$ & 102.93 & 12.52 & 87.00 & 125.00 \\
\hline Wordlist reading error $(\mathrm{z})^{\mathrm{b}}$ & -2.68 & 2.83 & -14.00 & 0.65 \\
\hline Wordlist reading time $(\mathrm{z})^{\mathrm{b}}$ & -4.23 & 5.43 & -27.90 & 2.20 \\
\hline Text reading time $(z)^{b}$ & -2.93 & 3.48 & -17.50 & 4.25 \\
\hline Text reading error $(z)^{b}$ & -4.42 & 5.13 & -25.00 & 0.14 \\
\hline Spelling performance $(\mathrm{z})^{\mathrm{c}}$ & -1.20 & 0.67 & -2.40 & 0.10 \\
\hline
\end{tabular}

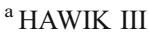

${ }^{\mathrm{b}}$ ZLT

${ }^{\mathrm{c}}$ SLRT or DRT5

Table 2 Behavioral pre-test data for the children with and without dyslexia in study 2

\begin{tabular}{|c|c|c|c|c|c|c|c|c|c|c|}
\hline \multirow[b]{2}{*}{ Measures } & \multicolumn{4}{|c|}{ With dyslexia $(n=37)$} & \multicolumn{4}{|c|}{ Without dyslexia $(n=25)$} & \multicolumn{2}{|c|}{$\begin{array}{l}\text { Mann-Whitney } \\
U \text { test }\end{array}$} \\
\hline & Mean & $\mathrm{SD}$ & Min & Max & Mean & SD & Min & Max & $\begin{array}{l}Z \\
\text { score }\end{array}$ & $\begin{array}{l}p \\
\text { Value }\end{array}$ \\
\hline Age (years) & 10.89 & 0.94 & 8.08 & 12.58 & 10.29 & 1.00 & 8.50 & 12.58 & 0.805 & 0.535 \\
\hline Grade level in school & 4.68 & 0.85 & 3.00 & 6.00 & 4.32 & 0.90 & 2.00 & 6.00 & -1.380 & 0.168 \\
\hline $\mathrm{IQ}^{\mathrm{a}}$ & 113.03 & 10.99 & 88.00 & 128.00 & 117.92 & 12.31 & 95.00 & 140.00 & -1.185 & 0.236 \\
\hline Verbal $\mathrm{IQ}^{\mathrm{a}}$ & 114.34 & 16.07 & 52.00 & 136.00 & 122.80 & 12.59 & 98.00 & 148.00 & -1.997 & 0.046 \\
\hline Performance $\mathrm{IQ}^{\mathrm{a}}$ & 105.89 & 17.81 & 39.00 & 144.00 & 109.64 & 14.17 & 88.00 & 135.00 & -0.751 & 0.453 \\
\hline Wordlist reading error $(\mathrm{z})^{\mathrm{b}}$ & -1.59 & 1.27 & -2.85 & 0.99 & 0.11 & 1.45 & -2.85 & 2.05 & -4.182 & $<0.001$ \\
\hline Wordlist reading time $(\mathrm{z})^{\mathrm{b}}$ & -1.96 & 0.99 & -2.85 & 0.30 & 0.06 & 1.31 & -2.35 & 2.50 & -5.115 & $<0.001$ \\
\hline Text reading time $(\mathrm{z})^{\mathrm{b}}$ & -1.81 & 0.99 & -2.85 & 1.17 & 0.06 & 0.83 & -1.48 & 1.75 & -5.719 & $<0.001$ \\
\hline Text reading error $(z)^{b}$ & -1.88 & 0.99 & -2.85 & -0.31 & -0.17 & 0.84 & -2.85 & 1.17 & -5.330 & $<0.001$ \\
\hline $\begin{array}{l}\text { Reading similar words: } \\
\text { pseudowords, time }(\mathrm{z})^{\mathrm{c}}\end{array}$ & -1.02 & 0.80 & -2.33 & 1.06 & 0.23 & 0.76 & -0.99 & 1.64 & -4.909 & $<0.001$ \\
\hline $\begin{array}{l}\text { Reading dissimilar words: } \\
\text { pseudowords, time }(\mathrm{z})^{\mathrm{d}}\end{array}$ & -0.87 & 0.86 & -2.58 & 1.06 & 0.29 & 0.95 & -1.75 & 1.64 & -4.240 & $<0.001$ \\
\hline Spelling performance $(z)^{\mathrm{d}}$ & -1.48 & 0.56 & -2.55 & 0.40 & -0.16 & 0.68 & -1.00 & 1.30 & -6.066 & $<0.001$ \\
\hline
\end{tabular}

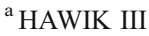

${ }^{\mathrm{b}}$ ZLT

c SLRT

${ }^{\mathrm{d}}$ SLRT or DRT5 
2000), which permitted the quantification of their reading skills. This reading test contained two subtests, namely, reading of wordlists and texts; performance was measured as time used and errors made. A German intelligence test named "HAWIK III" (Tewes \& Rossmann, 1999) was also administered, in order to assure average or above-average general cognitive skills in all subjects. In the second study, the aforementioned test battery was expanded with a pseudoword reading test from of the ("Salzburger-Lese und Rechtschreibtest SLRT").

To evaluate verbal memory functions, a verbal learning and retentivity test, that is, the "Verbaler Lern- \& Merkfähigkeitstest VLMT" (Lux, Helmstaedter, \& Elger 1999) was administered. This test measures learning performance, as well as short- and long-term memory by using word lists that must be repeated five times and recalled after half an hour.

The attention functions were tested by a version of computer-based program called KiTAP that is specifically designed to examine children (Zimmermann et al., 2002). This allowed us to test alertness, flexibility, and impulse control. Alertness forms a crucial role in attention intensity; it constitutes processes of the tonic and phaseal arousal (Posner \& Rafal, 1987). Flexibility is the aptitude to adapt to a new situation. The disability to realign focus attention causes preservative and stereotypical behavior (Lezak, 1995). Impulse control is the ability to refrain an inadequate reaction and is tested by a Go/No-Go Task (Drewe, 1975). While the KITAP computes the percentile of reaction time as a measure for alertness, the percentile of errors is used as a measure of flexibility and impulse control. Low scorers performed half a standard deviation below $(\leq 30 \%)$, and high scorers performed above $(\geq 70 \%)$ the mean for a given attention or memory function. The spelling tests were accomplished in a classroom setting. Reading, verbal memory, attention, and IQ tests were conducted in an individual test setting.

Children in the two studies performed the computer-based training for a period of 12 weeks. They were asked to practice about five times a week for 20 min each (see Table 3 for detailed information about how the training was monitored from the log-file data). No significant differences were found between the training times in the first 30 training days. The training generally took place on participants' home computers. Participants were offered the option of undergoing supervised training at our lab once a week. The meeting at our lab enabled us to monitor the data, which included checking children's working behavior and making sure that no technical problems occurred. For monitoring reasons, the parents of children who did not come to our lab once a week were requested to send us the log-file data. During training, the children worked at their own individual pace and were asked to learn up to 1,500 words with the level of difficulty corresponding to their elementary grade. The words contained various types of difficulties, which included: doubling of letters, such as, "Fall" (case), "Strasse" (street), and "Mutter" (mother); silent letters, for example, "Theater" (theater), "Zahl" (number), and "Saal" (hall); and

Table 3 Information about the training frequency (only spelling game) during the first 30 training days

\begin{tabular}{|c|c|c|c|c|c|c|c|}
\hline \multicolumn{2}{|c|}{ Mean over first 30 training days of: } & \multicolumn{2}{|c|}{$\begin{array}{l}\text { Training minutes } \\
\text { per session }\end{array}$} & \multicolumn{2}{|c|}{$\begin{array}{l}\text { Inputs (words) } \\
\text { per session }\end{array}$} & \multicolumn{2}{|c|}{$\begin{array}{l}\text { Total training } \\
\text { minutes }\end{array}$} \\
\hline & & Mean & SD & Mean & SD & Mean & SD \\
\hline First study & With dyslexia & 16.3 & 2.2 & 54.7 & 16.1 & 581.3 & 99.2 \\
\hline \multirow[t]{2}{*}{ Second study } & With dyslexia & 16.1 & 2.8 & 51.9 & 20.0 & 573.2 & 144.4 \\
\hline & Without dyslexia & 16.5 & 1.9 & 65.3 & 21.1 & 574.2 & 115.9 \\
\hline
\end{tabular}


diphthongs, such as, "Räuber" (thief), "Feuer" (fire), and "keine" (none), all belonging to the same group of phoneme-grapheme difficulties. Moreover, the words harbored other difficulties, which are caused by the visual similarity of letters ('d'-'b') or by the auditory similarity of phonemes $(/ \mathrm{n} /-/ \mathrm{m} /)$.

\section{Learning curves}

The concept of describing practice effects by simple nonlinear functions in a broad range of tasks is presented in Newell and Rosenbloom's Mechanisms of Skill Acquisition and the Law of Practice (Newell \& Rosenbloom, 1981). It has become a well-established procedure in the psychology of learning to analyze learning behavior based on such learning curves. However, there is an ongoing debate regarding which decay function best fits the relation between proficiency and number of practice trials. Based on the findings of Heathcote, Brown, and Mewhort (2000), we decided to rely on an exponential law of practice. This exponential law of practice describes the process of learning by an exponential decay function

$$
P_{e}(t)=a^{\prime} e^{-b t}+c
$$

where $P_{e}(t)$ represents the error probability at time $t$ (Heathcote et al., 2000). For our comparison of the different groups, we are interested in the initial error probability $\left(a=a^{\prime}+\right.$ $c$ : error probability at time $t=0)$, the learning progress ( $b$ : slope of the learning curve), and the asymptotic error probability ( $c$ : error probability for time $t \rightarrow \infty$ ). For sake of simplification, we performed the variable transformation $a=a^{\prime}+c$ and obtained the exponential decay function

$$
P_{e}(t)=(a-c) e^{-b t}+c .
$$

\section{Statistics}

The student model (Baschera et al., 2009) provides information about the amount of error possibilities in a word and describes the category of committed errors. To compare two groups of children on an error category, we compute the number of error possibilities $(W(t, g))$ and the number of committed errors $(C(t, g))$ of this category at day $t$ for each group $g$. For example, the word "Zahl" (number) contains five PGM error possibilities, such as "Tzahl", "Tsahl", "Zal", "Zaal" or "Zahll". In contrast, typing this word on a German keyboard entails 17 typing error possibilities. The values $(W(t, g))$ and $(C(t, g))$ are collected for the first 30 training days, i.e., we count only the days that the children were working with the training software. To exclude repetition effects from the analysis, we only consider the first prompt of each word. This procedure ensures that we only examine transfer effects from previously learned rules to newly encountered words. By dividing $(C(t, g))$ by $(W(t, g))$, we get the weighted mean error probability $P_{e}(t, g)$ of each group for the first 30 days. This expresses the probability that a child of a given group $g$ committed an error, if such a possibility occurred in a prompted word, at day $t$.

Then, we use a weighted nonlinear least-squares method to estimate the parameters of the exponential fit of both datasets. The number of error possibilities $(W(t, g))$ were used as weights for the estimation. To evaluate the significance of the difference between the two regressions, we run a combined estimation. Every parameter $p$ is replaced by a term $p\left(1+r_{p} g\right)$, consisting of an absolute parameter $p$ for the group $g=0$ and a relative parameter $r_{p}$, denoting the relative 
difference of the parameter $p$ for the first $(g=0)$ to the second $(g=1)$ group. This results in an estimation of the following form:

$$
P_{e}(t, g)=\left(a\left(1+r_{a} g\right)-c\left(1+r_{c} g\right)\right) e^{-b\left(1+r_{b} g\right) t}+c\left(1+r_{c} g\right)
$$

where $g$ equals zero for the first group and equals one for the second group. $r_{a}, r_{b}$, and $r_{c}$ indicate the relative difference between the corresponding parameters of the two groups and their $t$ tests return a measure for the significance of the difference.

To avoid an over-fitting to the data, we first reduced the above model for each comparison of the two groups. The reduction is performed by means of a backward model selection based on the Akaike information criterion (AIC) score (Akaike, 1974). In the Results section, the removed parameters will be marked by an " $\mathrm{R}$ ", which indicates that the model without those features represents the data the best. For example, if $r_{a}$ is mark by "R", the model considering no differences between the two investigated groups fits the data superiorly and the error probability $a$ is equal for both groups. All the regression analyses and model selections were computed with the statistical software R (R Development Core Team, 2005).

\section{Data analysis}

The data analyses are based on PGM errors. In orthographically nonshallow languages, such as, English and German, phonemes can be represented by different graphemes. Choosing a wrong grapheme representation for a phoneme is denoted as a phonemegrapheme matching error. The PGM errors reflect difficulties in the phoneme to grapheme mapping process. These are mostly additions or omissions of silent letters or doubling of letters and are a major difficulty for children with dyslexia. PGM errors account for approximately $30 \%$ of all committed errors during both studies. Since the different grapheme representations of a phoneme all sound the same, the correct matching has to be learnt by heart or by acquiring rules. Therefore, the progress in the PGM error probability is an appropriate measure for the learning behavior.

In contrast to PGM, typos are randomly occurring errors that are obviously not related to specific spelling difficulties of words. Typos account for approximately $40 \%$ of all the committed errors. Due to the randomness of typos and their independence of general spelling difficulties, we expect less progress over time. A detailed description of the different error categories provided by the student model can be found in (Baschera et al., 2009).

First, we compared the log-file data from the children with dyslexia in the first study to the children with dyslexia in the second study. The learning progress is evaluated by PGM errors, as well as typing errors, thus, enabling us to investigate whether the children could benefit from the phoneme-based enhancements of the spelling training software. Since the possibilities for PGM errors occur less frequently than for typing errors, the estimated errors probabilities of PGM errors $\left(P_{\mathrm{e}} \sim 0.02\right)$ are orders of magnitudes higher compared with typing errors $\left(P_{\mathrm{e}} \sim 0.001\right)$.

Second, we analyzed only the log-file data collected during the second study. We demonstrate the comparisons of children with and without dyslexia, as well as the comparison of different groups based on attention functions and verbal memory skills. In these analyses, we investigated the PGM errors.

For attention function and memory performance analysis, we classified all children based on their performance in the standardized neuropsychological tests, independent of their indication of dyslexia. To examine confounding effects between cognitive functions and the absence or the presence of the diagnosis of DD, we applied a $t$ test for independent samples. The outcome of this procedure demonstrated that there are no significant 
differences in the cognitive functions between the two groups (with vs. without dyslexia; see Table 4 for details). The number of children with and without dyslexia in each group is presented in the following table.

To further investigate how the subtests of the attention and memory functions are related to each other, we applied a parametric correlation analysis.

The results of the learning curve estimations are illustrated in the figures and tables below. If not stated otherwise, the black and red lines illustrate the fitted learning curves for both groups. The red and black points show the measured error probabilities at a given day for the two groups. The plotted error bars denote the $95 \%$ confidence intervals for the estimated probability measure of the analyzed error category at this day.

In the tables, the parameters of the first group are given in absolute values. The difference to the second group is displayed by a relative change. "Pr $(|t|)$ " shows the significance of each parameter. The "initial error probability" $(a)$ describes the probability of errors at the beginning of the study, which corresponds to the axis intercept. Additionally, $r_{a}$ represents the relative difference between the first and the second group. The "learning progress" $(b)$ demonstrates the slope of the learning curve and depicts the speed at which children improve during training. The relative difference of the slope between groups is named with $r_{b}$. "Asymptotic error probability" (c) indicates the limit of the children's training performance and $r_{c}$ characterizes the relative differences of this factor.

\section{Results}

Parametric correlation analysis of the attention and memory functions

The outcome of the parametric correlation analysis of the subtests of the attention and memory functions yielded that the subtests of the attention function alertness and flexibility correlated significantly $(r=0.277, p<0.05$; two-tailed). Additionally, this computation evidenced that all subtests of the memory functions correlated significantly with each other, such as learning performance with short-term memory $(r=0.652, p<0.01)$, learning performance with long-term memory $(r=0.595, p<0.01)$, and short-term memory with long-term memory $(r=0.761, p<0.01$; two-tailed). Notably, the main finding of this analysis yielded that attention functions were orthogonal to memory functions. None of the sub-test belonging to the attention function (alertness, flexibility, or impulse control) correlated significantly with any sub-test of the memory skills (learning performance, shortterm memory, or long-term memory). Since, our DD sample was, in addition, not

Table 4 Cognitive functions (memory and attention) comparisons for children with and without dyslexia

\begin{tabular}{|c|c|c|c|c|c|c|}
\hline & \multicolumn{2}{|c|}{ With dyslexia $(n=37)$} & \multicolumn{2}{|c|}{ Without dyslexia $(n=25)$} & \multicolumn{2}{|c|}{ Paired T-test } \\
\hline & Mean & $\mathrm{SD}$ & Mean & $\mathrm{SD}$ & $T$ Value & $p$ Value \\
\hline Alertness & 46.47 & 25.89 & 54.44 & 24.19 & -1.22 & 0.23 \\
\hline Flexibility & 46.46 & 32.67 & 52.62 & 33.84 & -0.72 & 0.48 \\
\hline Impulse control & 41.15 & 29.47 & 49.18 & 29.45 & -0.94 & 0.35 \\
\hline Learning performance & 46.07 & 30.86 & 51.40 & 30.16 & -0.67 & 0.50 \\
\hline Short-term memory & 55.82 & 29.81 & 58.10 & 28.53 & -0.30 & 0.77 \\
\hline Long-term memory & 59.73 & 26.47 & 61.10 & 25.78 & -0.20 & 0.84 \\
\hline
\end{tabular}


confounded with alertness functions or memory skills, we were able to investigate the influence of individual cognitive functions on the acquisition of spelling skills.

Children with dyslexia: first vs. second study

Figure 3 illustrates the probabilities of the PGM errors, as well as probabilities of the typing errors (typos) for children with dyslexia in the first and second studies. As expected, both groups with dyslexia start with the same error probability $\left(r_{a}=\mathrm{R}\right)$ and show no difference in the asymptotic error probability $\left(r_{c}=\mathrm{R}\right)$ for PGM errors (see Table 5). This result indicates that both groups have similar spelling skills at the beginning of the study and will attain the same limit in the training performance.

The main finding of this analysis is that the learning progress of the group who underwent spelling training with the new phoneme-enhanced software version was $154 \%$ higher than the progress of individuals who experienced training with the old spelling program. This shows that the children working with the new software version benefitted significantly more from the training: $(b: \operatorname{Pr}(>|t|)=2 e-7)$.

\section{Children with Dyslexia 1st vs. 2nd Study on PGM/Typo}

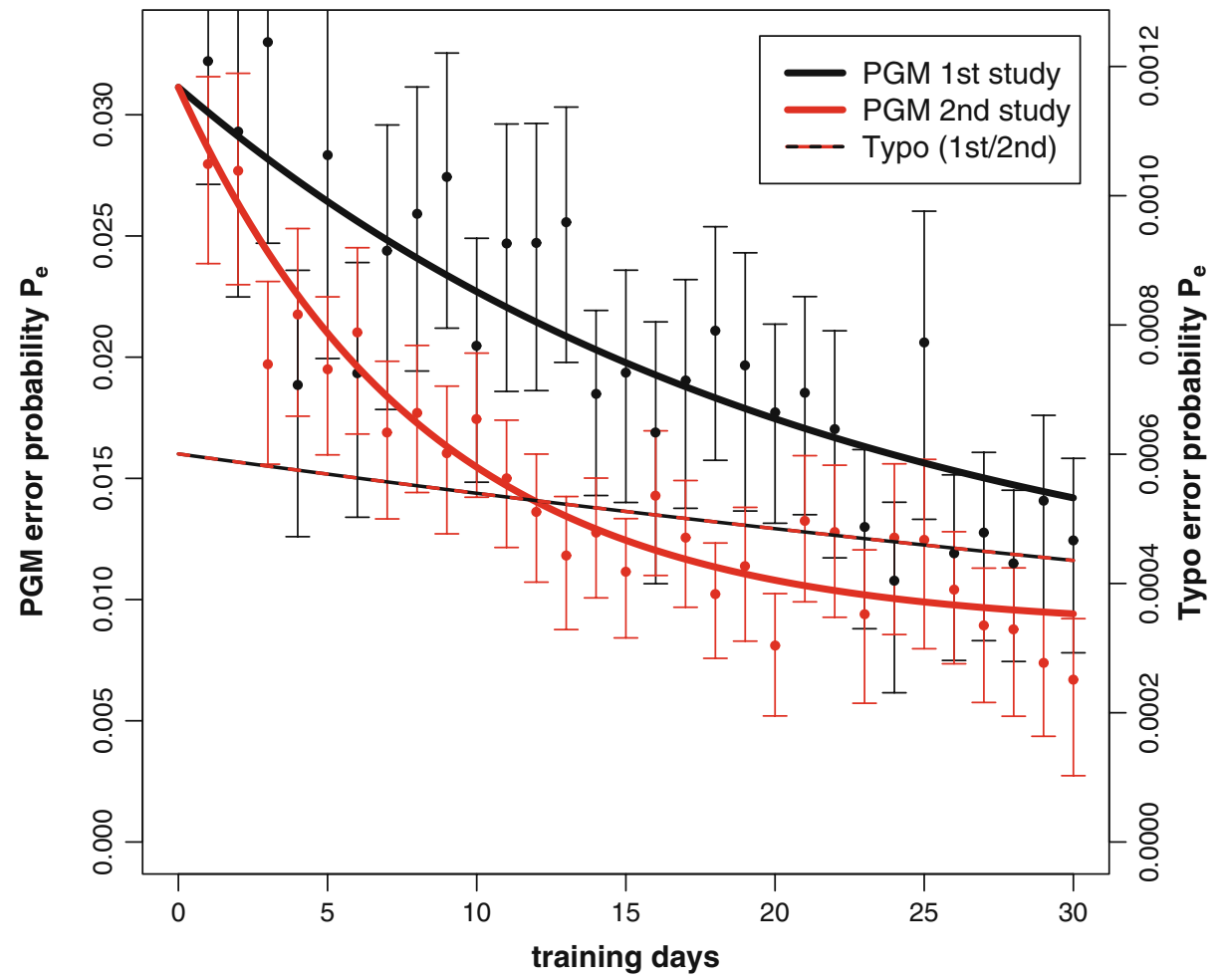

Fig. 3 The bold black and red lines illustrate the fitted learning curves for the children with dyslexia from the first study (black) and second study (red). The points and error bars illustrate the PGM error probability estimate for a given day and its $95 \%$ confidence intervals. The spelling improvement of individuals with dyslexia from the second study (vs. first study) on PGM was significantly higher; however, in both groups, the same typing error behavior was observed. Learning curves of PGM errors (left $Y$-axis) and typos (right $Y$-axis) for the children with dyslexia from the first and second studies 
Table 5 PGM errors and typo results for participants with dyslexia in studies 1 and 2

\begin{tabular}{|c|c|c|c|c|c|c|c|c|}
\hline & & \multicolumn{2}{|c|}{$\begin{array}{l}\text { Initial error } \\
\text { probability }\end{array}$} & \multicolumn{2}{|c|}{ Learning progress } & \multicolumn{2}{|c|}{$\begin{array}{l}\text { Asymptotic error } \\
\text { probability }\end{array}$} & \multirow[t]{3}{*}{$R^{2}$ values } \\
\hline & & $a$ Value & $\operatorname{Pr}(>|t|)$ & $b$ Value & $\operatorname{Pr}(>|t|)$ & $c$ Value & $\operatorname{Pr}(>|t|)$ & \\
\hline & & $r_{a}$ Value & $\operatorname{Pr}(>|t|)$ & $r_{b}$ Value & $\operatorname{Pr}(>|t|)$ & $r_{c}$ Value & $\operatorname{Pr}(>|t|)$ & \\
\hline \multicolumn{9}{|l|}{ PGM } \\
\hline First study & (abs.) & 0.031 & $2 \mathrm{e}-16$ & 0.050 & 7e-09 & 0.0091 & $7 e-12$ & 0.788 \\
\hline Second study & (rel.) & $\mathrm{R}$ & & $+154 \%$ & $2 \mathrm{e}-07$ & $\mathrm{R}$ & & 0.907 \\
\hline \multicolumn{9}{|l|}{ Туро } \\
\hline First study & (abs.) & 0.0006 & $2 \mathrm{e}-16$ & 0.011 & 0.0039 & $\mathrm{R}$ & & 0.399 \\
\hline Second study & (rel.) & $\mathrm{R}$ & & $\mathrm{R}$ & & $\mathrm{R}$ & & 0.752 \\
\hline
\end{tabular}

Table 5 also illustrates that the probability of committing a typo $(a=0.0006)$, if such a possibility occurs, is significantly less than for PGMs $(a=0.031)$. The analysis of the typos revealed that both groups commit approximately the same number of typing errors at the beginning $\left(r_{a}=\mathrm{R}\right)$ and at the end $\left(r_{c}=\mathrm{R}\right)$ of the training. Additionally, the two groups reduced their typos to the same extent $\left(r_{b}=\mathrm{R}\right)$. A significant decrease of typos was observed during the training; however, the learning progress on PGM $(b=0.05)$ as compared with typos $(b=0.011)$ was substantially higher.

\section{Children with vs. without dyslexia}

Figure 4 presents the learning curves of PGM errors for children with and without dyslexia, who participated in the second study. As Table 6 depicts, children without dyslexia (as compared with children with dyslexia) showed $21.8 \%$ fewer spelling errors at the beginning of the training; they are beginning with a significantly lower initial error probability $\left(r_{a}: \operatorname{Pr}(>|t|)=5 \mathrm{e}-08\right)$. Our main finding is that both groups were able to significantly improve their spelling proficiency during the training, $(b: \operatorname{Pr}(>|t|)=3 \mathrm{e}-08)$. Importantly, both groups were able to improve their spelling proficiency to the same extent $\left(r_{b}=\right.$ R). Furthermore, children without dyslexia as compared with children with dyslexia showed a slightly lower asymptotic error probability, $\left(r_{c}: \operatorname{Pr}(>|t|)=0.04\right)$.

\section{Attention functions}

In a further step, we analyzed the attention functions influencing the phoneme-graphememapping progress, which involved comparing children with low attention functions to children with high attention functions, based on the data of the second study. As displayed in Table 7, our data showed that children with high compared with low impulse control $\left(r_{a}=-47.0 \%, \operatorname{Pr}(>|t|)=1 \mathrm{e}-14\right)$, flexibility $\left(r_{a}=-46.4 \%, \operatorname{Pr}(>|t|)=2 \mathrm{e}-16\right)$, and alertness scores $\left(r_{a}=-12.3 \%, \operatorname{Pr}(>|t|)=0.0038\right)$ committed significantly fewer spelling errors at the beginning of the training. Notably, children with low attention functions (i.e., impulse control $\left(r_{b}=\mathrm{R}\right)$, flexibility $\left(r_{b}=\mathrm{R}\right)$, and alertness $\left.\left(r_{b}=\mathrm{R}\right)\right)$ were able to benefit from the training to the same degree as the corresponding high attention score group. Additionally, the two groups did not differ in their asymptotic error probability in all attention functions $\left(r_{c}=\mathrm{R}\right)$. Therefore, it can be expected that children with high vs. low 


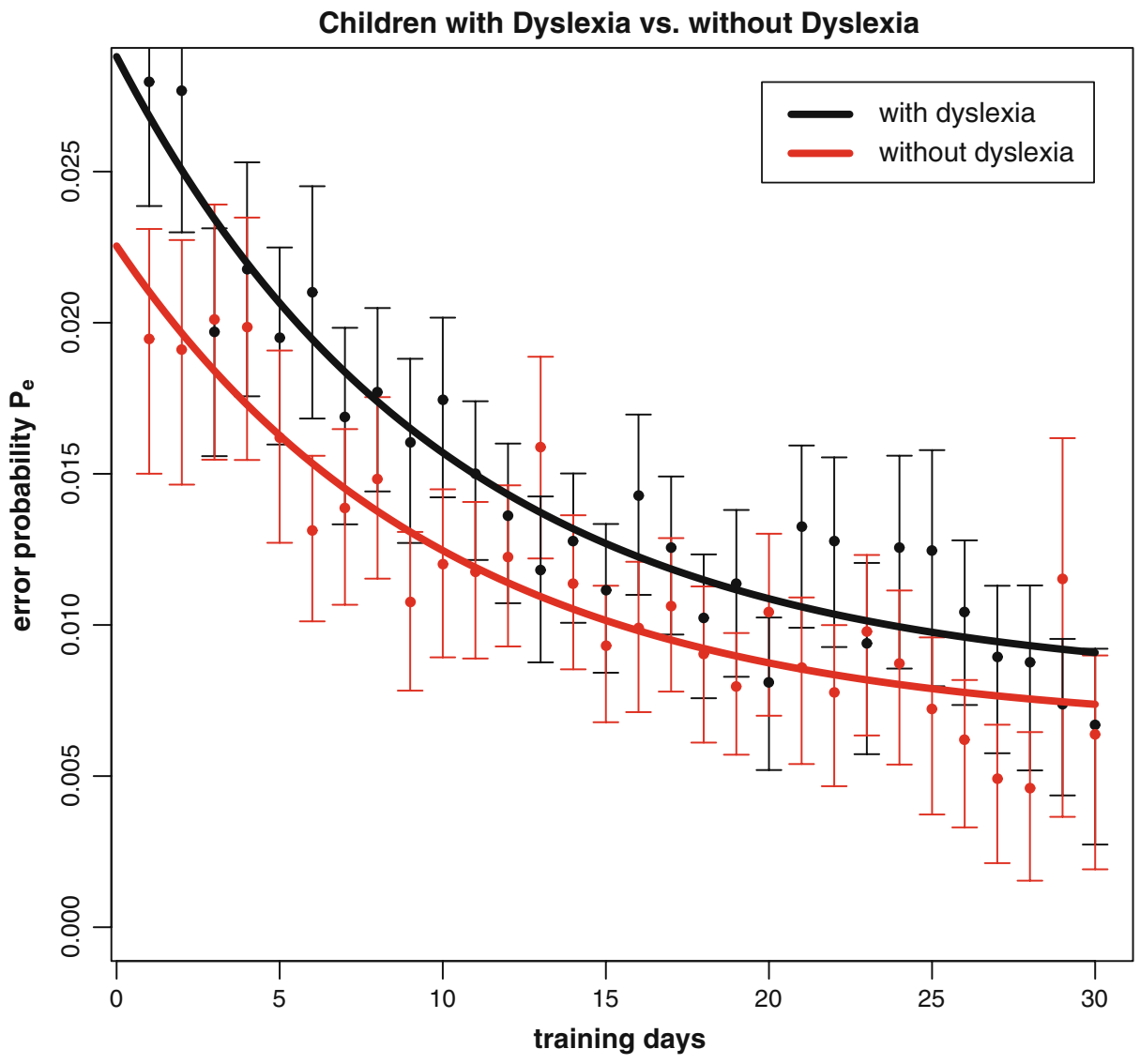

Fig. 4 Both groups were able to improve their spelling skills to the same extent. Learning curves for PGM errors of the children with and without dyslexia from the second study

attention functions will attain the same spelling level. Figure 5 illustrates the learning curves for the comparison of the groups with high and low impulse control.

Memory skills

Children with high vs. low learning performance, short-term memory, as well as long-term memory scores all started at the same level (see, for details, Table 8); however, compared

Table 6 Results of the PGM errors for the children with and without dyslexia

\begin{tabular}{|c|c|c|c|c|c|c|c|c|}
\hline & & \multicolumn{2}{|c|}{$\begin{array}{l}\text { Initial error } \\
\text { probability }\end{array}$} & \multicolumn{2}{|c|}{ Learning progress } & \multicolumn{2}{|c|}{$\begin{array}{l}\text { Asymptotic error } \\
\text { probability }\end{array}$} & \multirow[t]{3}{*}{$R^{2}$ Value } \\
\hline & & $a$ Value & $\operatorname{Pr}(>|t|)$ & $b$ Value & $\operatorname{Pr}(>|t|)$ & $c$ Value & $\operatorname{Pr}(>|t|)$ & \\
\hline & & $r_{a}$ Value & $\operatorname{Pr}(>|t|)$ & $r_{b}$ Value & $\operatorname{Pr}(>|t|)$ & $r_{c}$ Value & $\operatorname{Pr}(>|t|)$ & \\
\hline With dyslexia & (abs.) & 0.029 & $2 \mathrm{e}-16$ & 0.100 & $3 e-08$ & 0.0080 & $7 e-10$ & 0.908 \\
\hline Without dyslexia & (rel.) & $-21.8 \%$ & $5 e-08$ & $\mathrm{R}$ & & $-18.3 \%$ & 0.040 & 0.818 \\
\hline
\end{tabular}


Table 7 Results of attention functions influence on PGM progress

\begin{tabular}{|c|c|c|c|c|c|c|c|}
\hline & \multicolumn{2}{|c|}{$\begin{array}{l}\text { Initial error } \\
\text { probability }\end{array}$} & \multicolumn{2}{|c|}{ Learning progress } & \multicolumn{2}{|c|}{$\begin{array}{l}\text { Asymptotic error } \\
\text { probability }\end{array}$} & \multirow[t]{3}{*}{$R^{2}$ Value } \\
\hline & $a$ Value & $\operatorname{Pr}(>|t|)$ & $b$ Value & $\operatorname{Pr}(>|t|)$ & $c$ Value & $\operatorname{Pr}(>|t|)$ & \\
\hline & $r_{a}$ Value & $\operatorname{Pr}(>|t|)$ & $r_{b}$ Value & $\operatorname{Pr}(>|t|)$ & $r_{c}$ Value & $\operatorname{Pr}(>|t|)$ & \\
\hline Impulse control & \multicolumn{7}{|c|}{ (Below, 11 with dyslexia/4 without dyslexia; above, 6 with dyslexia/6 without dyslexia) } \\
\hline Below $N$ (abs.) & 0.032 & $2 \mathrm{e}-16$ & 0.074 & $2 \mathrm{e}-06$ & 0.0066 & $2 \mathrm{e}-05$ & 0.815 \\
\hline Above $N$ (rel.) & $-47.0 \%$ & $1 \mathrm{e}-14$ & $\mathrm{R}$ & & $\mathrm{R}$ & & 0.464 \\
\hline Flexibility & \multicolumn{7}{|c|}{ (Below, 14 with dyslexia/5 without dyslexia; above, 13 with dyslexia/8 without dyslexia) } \\
\hline Below $N$ (abs.) & 0.042 & $2 \mathrm{e}-16$ & 0.127 & $5 e-11$ & 0.0085 & $3-16$ & 0.848 \\
\hline Above $N$ (rel.) & $-46.4 \%$ & $2 \mathrm{e}-16$ & $\mathrm{R}$ & & $\mathrm{R}$ & & 0.837 \\
\hline Alertness & \multicolumn{7}{|c|}{ (Below, 11 with dyslexia/5 without dyslexia; above, 7 with dyslexia/8 without dyslexia) } \\
\hline Below $N$ (abs.) & 0.028 & $2 \mathrm{e}-16$ & 0.044 & $2 \mathrm{e}-16$ & $\mathrm{R}$ & & 0.754 \\
\hline Above $N$ (rel.) & $-12.3 \%$ & 0.0038 & $\mathrm{R}$ & & $\mathrm{R}$ & & 0.798 \\
\hline
\end{tabular}

with low scorers, children with high scores in learning performance $\left(r_{b}=+126 \%\right.$, $\operatorname{Pr}(>|t|)=0.0016)$, short-term memory functions $\left(r_{b}=+175 \%, \operatorname{Pr}(>|t|)=0.0015\right)$, and long-term memory functions $\left(r_{b}=+226 \%, \operatorname{Pr}(>|t|)=8 \mathrm{e}-05\right)$ exhibited significantly decreased spelling errors during the training. Conversely, the asymptotic error probability did not differ significantly between groups. Figure 6 displays the difference between high and low learning performance.

\section{Discussion}

This study was designed to investigate the learning curves of children who worked with a computer-based spelling training system. First, we aimed to evaluate the efficiency of additional phonological-based information implemented in the new version. Second, we analyzed spelling and learning behavior of children with and without dyslexia. Third, we investigated the influence of cognitive functions, such as memory and attention, on the learning progress.

Children with dyslexia: first vs. second study

The most interesting finding of the first analysis was that children with dyslexia who worked with the new software version, compared with children with dyslexia who worked with the first software version, significantly increased their learning performance on PGM errors by $+154 \%$. The fact that the children with dyslexia in the first and second study show comparable initial and asymptotic error probabilities on PGM underpins the notion that the two groups did not differ from each other a priori. This result evidences that the phonemebased enhancements, such as textural code and adjusted controller, supported the children with their learning behavior.

The additional textural code is implemented based on the notion that the core problem of DD is a phonological processing deficit. This deficit becomes manifest in reduced phoneme to grapheme mapping skills (Byrne, 1998; Ramus et al., 2003). The additional textural code provides supplementary information to the topological code. Whereas the topological code syllabifies the word, the textural code supplies easily extractable information about the 


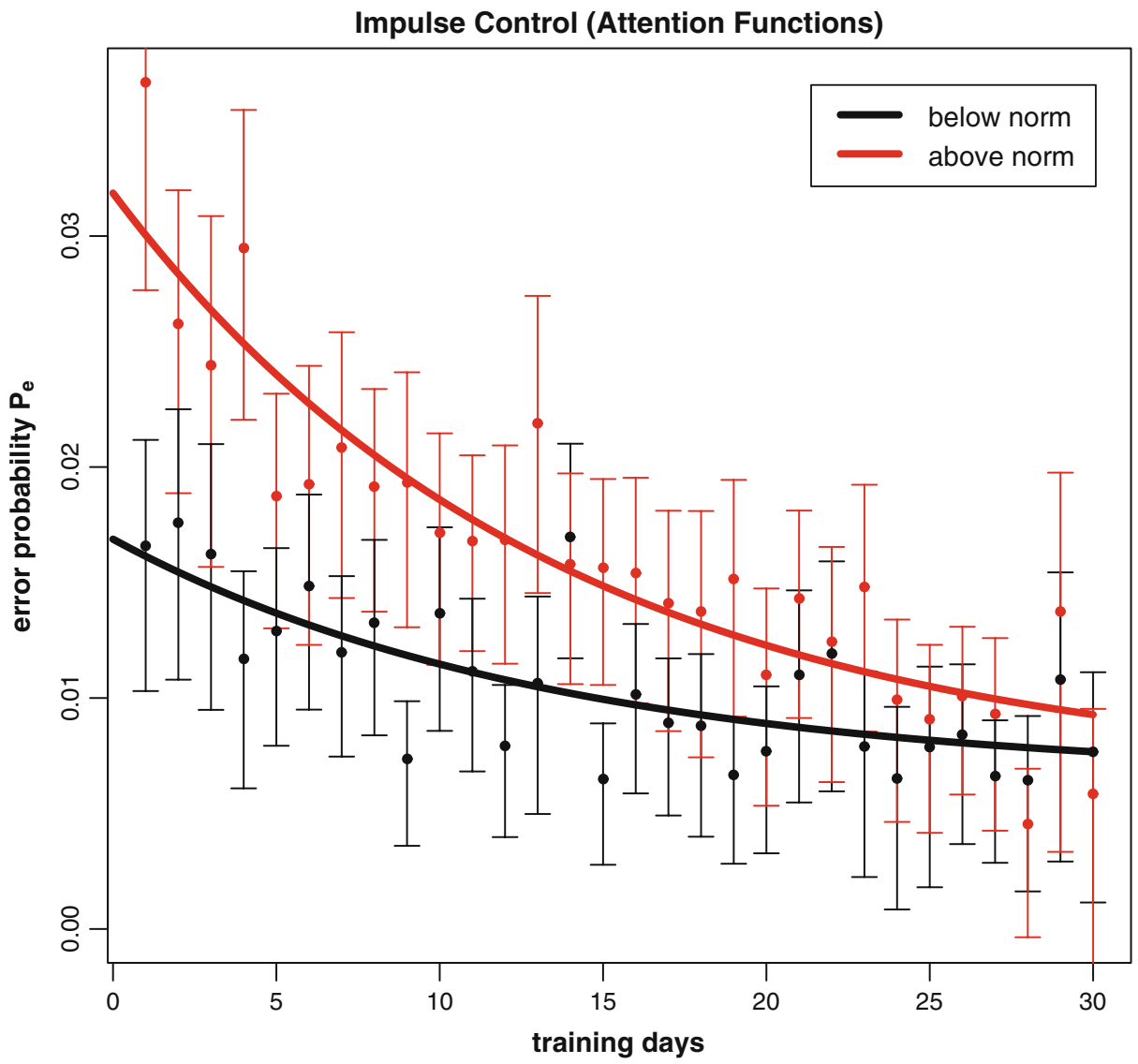

Fig. 5 Low vs. high scorers can benefit similarly from the structured environment and the implemented audio-visual codes of the learning software. Learning curves for children with high and low impulse control scores on PGM errors

Table 8 Results of memory performances influence on PGM progress

\begin{tabular}{|c|c|c|c|c|c|c|c|c|}
\hline & & \multicolumn{2}{|c|}{$\begin{array}{l}\text { Initial error } \\
\text { probability }\end{array}$} & \multicolumn{2}{|c|}{ Learning progress } & \multicolumn{2}{|c|}{$\begin{array}{l}\text { Asymptotic error } \\
\text { probability }\end{array}$} & \multirow[t]{2}{*}{$R^{2}$ Value } \\
\hline & & $\begin{array}{l}a \text { Value } \\
r_{a} \text { Value }\end{array}$ & $\begin{array}{l}\operatorname{Pr}(>|t|) \\
\operatorname{Pr}(>|t|)\end{array}$ & $\begin{array}{l}b \text { Value } \\
r_{b} \text { Value }\end{array}$ & $\begin{array}{l}\operatorname{Pr}(>|t|) \\
\operatorname{Pr}(>|t|)\end{array}$ & $\begin{array}{l}c \text { Value } \\
r_{c} \text { Value }\end{array}$ & $\begin{array}{l}\operatorname{Pr}(>|t|) \\
\operatorname{Pr}(>|t|)\end{array}$ & \\
\hline \multicolumn{2}{|c|}{ Learning performance } & \multicolumn{7}{|c|}{ (Below, 14 with dyslexia/7 without dyslexia; above, 9 with dyslexia/7 without dyslexia) } \\
\hline Below $N$ & (abs.) & 0.026 & $2 \mathrm{e}-16$ & 0.079 & $2 \mathrm{e}-8$ & 0.0072 & $2 \mathrm{e}-12$ & 0.777 \\
\hline Above $N$ & (rel.) & $+12.7 \%$ & 0.212 & $+126 \%$ & 0.0016 & $\mathrm{R}$ & & 0.908 \\
\hline Short-term & & \multicolumn{4}{|c|}{ (Below, 10 with dyslexia/6 without dyslexia; abov } & \multicolumn{3}{|c|}{12 with dyslexia/10 without dyslexia } \\
\hline Below $N$ & (abs.) & 0.022 & $2 \mathrm{e}-16$ & 0.036 & $2 \mathrm{e}-05$ & 0.0051 & 0.0017 & 0.602 \\
\hline Above $N$ & (rel.) & $+15.9 \%$ & 0.090 & $+175 \%$ & 0.0015 & $\mathrm{R}$ & & 0.901 \\
\hline Long-term & & \multicolumn{7}{|c|}{ (Below, 7 with dyslexia/5 without dyslexia; above, 12 with dyslexia/9 without dyslexia) } \\
\hline Below $N$ & (abs.) & 0.025 & $2 \mathrm{e}-16$ & 0.039 & $5 \mathrm{e}-05$ & 0.0064 & $3 e-06$ & 0.454 \\
\hline Above $N$ & (rel.) & $\mathrm{R}$ & & $+226 \%$ & $8 \mathrm{e}-05$ & $\mathrm{R}$ & & 0.851 \\
\hline
\end{tabular}




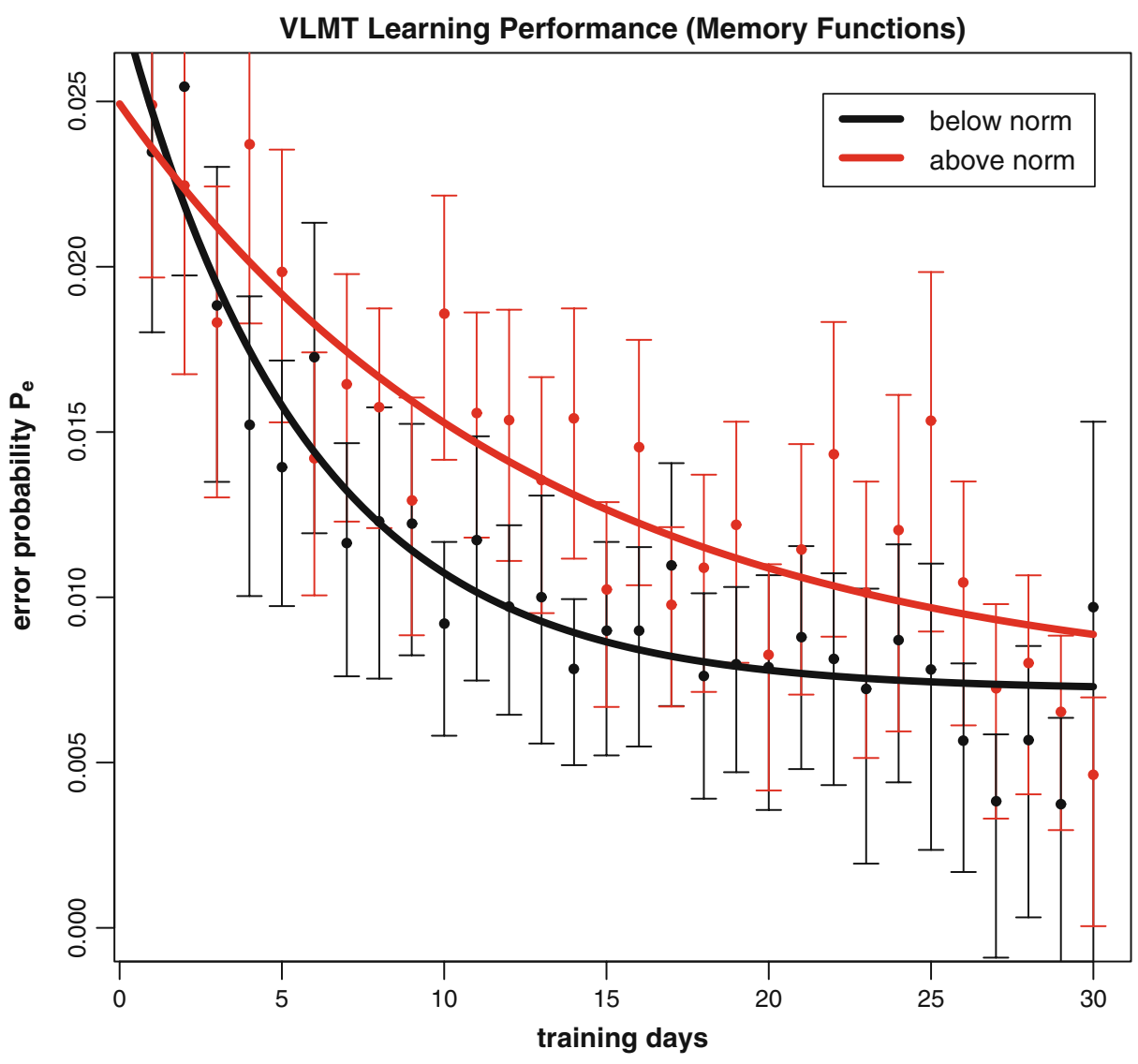

Fig. 6 Children with high, compared with low memory skills, significantly reduced their error probability. Learning curves for children with high and low verbal learning performance (VLMT) on PGM errors

phonological word structure (see textural code on Figs. 1 and 2). This results in a segmentation of the word in phonemes and supports the association with their graphemes. The visualization of the association between phonemes and graphemes strengthens the phonological awareness similar to the audio-visual phoneme discrimination task used in the software that has been evaluated by Ecalle et al. (2009).

We believe that another important factor responsible for the enhancement of the spelling skills was the phoneme-based word selection controller. This controller identifies the children's individual difficulties based on their error behavior and prompts words containing these problems. In contrast to M. Bodén and M. Bodén's (2007) evolutionary approach to word selection, which lacks an error localization or classification, and to the old word selection method of (REF), which relies on a letter-based analysis of errors, the new controller accounts for spelling difficulties on a phonological level. For example, if a child struggles with spelling the word "Zahl" (number) because it does not know that the word contains a silent "h", then the controller selects and prompts more words containing silent sounds, such as "sehr" (very) or "ahnen" (guess). Therefore, the child is repeatedly confronted with his/her individual spelling problems. Consequently, the child learns the linguistic spelling rules based on the German language and generalizes them to other words after training. 
In a supplementary analysis, we investigated the error behavior on typos. The error probability of randomly occurring typing errors is several orders of magnitudes lower than the PGM error probability. Contrary to the group differences in PGM errors, the error behavior as regards typos did not differ between the first and second group of participants with dyslexia.

Moreover, the analysis of typos indicated that in both groups the children slightly decreased their typing error probability. This slight improvement can be explained by the lack of experience of 8- to 12-year-old children in working at a keyboard. We assume that the children gained knowledge about the key distribution on the keyboard through training, which resulted in a weak reduction of the typing errors probability.

Children with vs. without dyslexia

Our data demonstrate that the multi-modal training induced a significant decrease in spelling errors, particularly phoneme-grapheme matching errors, in both children with and without dyslexia. This progress was found for words that were presented for the first time. Therefore, children with dyslexia, as well as children without dyslexia showed that they not only memorized the word form of the target words (i.e., correct spelling) but that they were able to generalize concepts and adopt rules based on the German language. The most significant effect yielded from this research study was that both children with dyslexia and children without dyslexia exhibited the same learning progress, although children with dyslexia were characterized by a significantly higher initial spelling error probability. These results evidenced that both groups benefited from the training and improved their phoneme-grapheme conversion knowledge. Moreover, we suggest that the visual and auditory feedback provided by our spelling program exclusively aids subjects with memorizing the correct word form.

Learning to read and spell requires memorizing and applying the phoneme-grapheme correspondence forwards or backwards. It has been suggested that learning to read and spell permanently changes the nature of phonological representations in the brain (Goswami et al., 2005) and that these orthographically shaped phonological networks are directly linked to additional visuo-orthographical networks. Finding the same learning curve in both groups indicates that children with and without dyslexia can benefit in similar ways from the multi-modal, nonverbal cues implemented in the training software.

Children with dyslexia are characterized by poor phonological awareness, which is attributed to difficulties in memorizing the phoneme-grapheme associations. Since it is known that individuals with dyslexia use a nonphonological, visual coding strategy for memorizing information (Miller \& Kupfermann, 2009), we linked the culturally determined association between phoneme and grapheme with a nonverbal visual code. Therefore, individuals with dyslexia are faced with a naturally occurring visual coding strategy that facilitates the memorization of the word form.

Our data analysis points out that, although children with and without dyslexia might have different memorizing strategies, as proposed by Miller and Kupfermann (2009), both groups were able to form "memory traces" in long-term memory for orthography and general orthographic rules based on the German language. It has been suggested that it is more effective to teach children with reading difficulties the phoneme-grapheme correspondence by employing a method that models connections between written and spoken words, as opposed to using a phonics rule based approach (Berninger et al., 1999). These modeled connections support to create associative links between orthographic input representations and phonological output representations. Thus, repeated presentations of orthographic forms drive phonological responses. Berninger et al. (1999) state that, when 
explicit modeling of grapheme-phoneme connections for multi-letter spelling units are taught from the beginning of formal instructions in reading, confusion can be avoided. Additionally, they assume that children with impaired phonological or orthographic awareness might benefit from color-coded spelling units (Berninger et al., 1999).

Further analysis

In a further step, we aimed to identify the cognitive abilities responsible for acquiring spelling performances. We assume that successful learning is guided by attention and memorizing performances. Accordingly, we analyzed different attention functions (alertness, flexibility, and impulse control), as well as memory performances (learning progress, short-term memory functions, and long-term memory functions), in order to examine which cognitive components affect the acquiring of spelling skills. Respectively, our analyses demonstrate that children benefit from the structured learning environment of the learning software.

\section{Attention functions}

Generally, we found that children with low vs. high attention scores (impulse control, flexibility, and alertness) committed significantly more spelling errors at the beginning of the training. These findings indicate that low scorers had not benefited as much from traditional teaching and schooling in orthography as high scorers; however, both groups (low and high attention scores) benefited from the computer-based training to the same extent. In addition, the same skill level could be expected to be seen in both groups as a result of this training.

We suggest that working on the computer facilitates children to structure their working strategy and supports them with focusing on the relevant task. The structural guidance is enforced with the interface of the topological code, which assists the users in their serial behavior of putting the correct letters in the right position. The support with focusing the attention on the relevant stimulus might be beneficial for children with reduced attention functions. Our findings are in line with previous evidence that children with ADHD can also improve their spelling skills when a clear strategy is taught (Re, Caeran, \& Cornoldi 2008).

\section{Memory functions}

In our analysis of spelling curves, we aimed to examine the influence of memory performances on spelling skills. Our data indicates that children with high and low memory performance start at the same spelling level and will reach the same limit at the end of the study. However, children with high (vs. low) verbal learning progress and short- and longterm memory scores benefited significantly more from the computer-based training. These results are consistent with the notion that children's abilities to store and manipulate information in complex memory performances may have strong influence on learning; furthermore, these abilities may be associated with scholastic attainment during their school career (Gathercole, Alloway, Willis, \& Adams 2006). Children with poor verbal memory skills, therefore, show specific impairments in the process of learning the phonological structures of new vocabulary items (Baddeley, Gathercole, \& Papagno 1998). Long-term memory can be considered a crucial cognitive function that subserves phonological, grapheme, and lexical representations. Consequently, long-term memory has a strong influence on learning reading and spelling skills. 
In summary, our data evidences that children with high memory performance benefited greatly from the information provided by the learning software as it strengthens the retrieval of letters or phonemes stored in memory structures. Additionally, our data evidence that acquiring orthographic knowledge requires memory resources.

\section{Limitations and further research}

Our data was collected by a computer-based training program that supports children's spelling behavior by using visual and auditory codes. The transfer to a paper-pencil test is not demonstrated in the present work because we demonstrated previously (REF) that both children with and without dyslexia could improve their spelling skills. Spelling improvements were observed for both learned and non-learned words.

The software presented in the current study permits children to work independently according to their own learning pace. Since the software adapts to the individual level, it can be considered as a complement to traditional teacher supervised learning. The presently available data implies that this training should also be effective in a classroom setting, if the infrastructure (enough computers) is available. Nevertheless, working with a computer neglects important influences on social and emotional aspects on learning.

Although children with dyslexia benefit from the information provided by the actual version of the learning software, the data show that they still do not reach the same level as children without dyslexia. The treatment of DD is longstanding and further training is needed. Since children with low reading and spelling skills have to work hard to improve their orthographic knowledge, motivation has a great impact on learning behavior. To maintain children's motivation to continue the training, which, in turn, may result in enhanced spelling skills, the provision of external and internal rewards might play a crucial role. Hence, it would be of interest to further investigate motivational aspects that may be involved by implementing different rewarding systems in the learning software. Provision of rewards, as well as the resulting motivation should also be examined in relation to personality traits.

\section{Conclusion}

Our results demonstrate that the additional textural cue, visualization of the phonemes, and the new phoneme-based word selection controller, which were adapted to individual difficulties, positively influenced the spelling performance of children with dyslexia. Additionally, there is evidence that both children with and without dyslexia profit from the computer-based training in a similar way. Both groups were able to use the visual and auditory coding system implemented in the learning software to acquire spelling skills. Children with dyslexia were able to strengthen their memories of grapheme to phoneme correspondence. As a result, we suggest that abstract visual and auditory cues facilitated the memorization of phonological information. Similarly, children with low (vs. high) attentional performances could benefit equally from the structured computer-based learning software. This finding implicates that children with low attention resources need clear guidance and may benefit from a structured methodological approach. Moreover, we were able to show that the usage of information cues requires memory skills. In addition, memory functions correlate positively with learning progress irrespective of dyslexia. This indicates that memory functions are important cognitive sources for acquiring spelling skills. 
Acknowledgment This project was supported by the Research Funding University of Zurich (56234102), the SNF-grant 320000-120661/1, and the CTI-grant 8970.1.

\section{References}

Adams, M. J. (1990). Beginning to read: Thinking and learning about print. Cambridge: MIT Press.

Akaike, H. (1974). A new look at the statistical model identification. Automatic Control, IEEE Transactions on, 19, 716-723.

Annett, M. (1970). A classification of hand preferences by association analysis. British Journal of Psychology, 61, 303-321.

Baddeley, A., Gathercole, S., \& Papagno, C. (1998). The phonological loop as a language learning device. Psychological Review, 105(1), 158-173.

Baldeweg, T., Richardson, A., Watkins, S., Foale, C., \& Gruzelier, J. (1999). Impaired auditory frequency discrimination in dyslexia detected with mismatch evoked potentials. Annals of Neurology, 45(4), 495-503.

Baschera, G. M., \& Gross, M. (2009). A Phoneme-Based Student Model for Adaptive Spelling Training. Paper presented at the In Proceedings of Artificial Intelligence in Education.

Berninger, V. W., Abbott, R. D., Zook, D., Ogier, S., Lemos-Britton, Z., \& Brooksher, R. (1999). Early intervention for reading disabilities. Journal of Learning Disabilities, 32(6), 491-503.

Bodén, M., \& Bodén, M. (2007). Evolving spelling exercises to suit individual student needs. Applied Sort Computing, 7, 126-135.

Bradley, L., \& Bryant, P. E. (1983). Categorizing sounds and learning to read-a causal connection. Nature, $301,419-421$.

Byrne, B. (1998). The foundation of literacy: The child's acquistion of the alphabetic principle. East Sussex UK: Psychology Press.

Crespo Garcia, R. M., Delgado Kloos, C., \& Castro Gil, M. (2008). Game based spelling learning. Paper presented at the 38th ASSEE/IEEE Frontiers in Education Conference. Saratoga Springs, NY.

Drewe, E. A. (1975). Go-nogo learning after frontal lobe lesions in humans. Cortex, 11, 8-16.

Ecalle, J., Magnan, A., Bouchafa, H., \& Gombert, J. E. (2009). Computer-based training with orthophonological units in dyslexic children: New investigations. Dyslexia, 15(3), 218-238.

Farmer, M. E., \& Klein, R. M. (1995). The evidence for a temporal processing deficit linked to dyslexia: A review. Psychonomic Bulletin \& Review, 2, 460-493.

Frith, U. (1985). Beneath the surface of developmental dyslexia surface dyslexia. In K. E. Patterson, J. C. Marshall, \& M. Coltheart (Eds.), Neurophysiological and cognitive studies of phonological reading (pp. 301-327). London: Erlbaum.

Gascon, G., \& Goodglass, H. (1970). Reading retardation and the information content of stimuli in paired associate learning. Cortex, 6(4), 417-429.

Gathercole, S. E., Alloway, T. P., Willis, C., \& Adams, A.-M. (2006). Working memory in children with reading disabilities. Journal of Experimental Child Psychology, 93(3), 265-281.

Goswami, U., Ziegler, J. C., \& Richardson, U. (2005). The effects of spelling consistency on phonological awareness: A comparison of English and German. Journal of Experimental Child Psychology, 92(4), 345-365.

Goyen, J. D., \& Lyle, J. G. (1971). Effect of incentives upon retarded and normal readers on a visualassociated learning task. Journal of Experimental Child Psychology, 11(2), 274-280.

Gross, M., \& Voegeli, C. (2007). A multimedia framework for effective language training. Computers \& Graphics, 31, 761-777.

Grund, M., Haug, G., Naumann, C. L., \& Weinheim, B.-V. (1995). Diagnostischer Rechtschreibtest 5. Klasse. Weinheim: Beltz-Verlag.

Heathcote, A., Brown, S., \& Mewhort, D. J. (2000). The power law repealed: The case for an exponential law of practice. Psychonomic Bulletin \& Review, 7(2), 185-207.

Hilte, M., \& Reitsma, P. (2006). Spelling pronunciation and visual preview both facilitate learning to spell irregular words. Annals of Dyslexia, 56(2), 301-318.

Hulme, C., Goetz, K., Gooch, D., Adams, J., \& Snowling, M. J. (2007). Paired-associate learning, phoneme awareness, and learning to read. Journal of Experimental Child Psychology, 96(2), 150-166.

Huss, M., Verney, J. P., Fosker, T., Mead, N., \& Goswami, U. (2010). Music, rhythm, rise time perception and developmental dyslexia: Perception of musical meter predicts reading and phonology. Cortex, (In Press). Corrected Proof.

Kast, M., Meyer, M., Vogeli, C., Gross, M., \& Jancke, L. (2007). Computer-based multisensory learning in children with developmental dyslexia. Restorative Neurology and Neuroscience, 25(3-4), 355-369. 
Kujala, T., Karma, K., Ceponiene, R., Belitz, S., Turkkila, P., Tervaniemi, M., et al. (2001). Plastic neural changes and reading improvement caused by audiovisual training in reading-impaired children. Proceedings of the National Academy of Sciences of the United States of America, 98(18), 10509-10514.

Landerl, K., Wimmer, H., \& Moser, E. (1997). Der Salzburger Lese- und Rechtschreibtest (SLRT). Bern: Verlag Hans Huber.

Lashley, K. S. (1951). The problem of serial order in behavior. In F. Beach, D. Hebb, C. Morgan, \& H. Nissen (Eds.), The neuropsychology of Lashley 1960 (pp. 506-528). New York: McGraw-Hill.

Lehmann, S., \& Murray, M. M. (2005). The role of multisensory memories in unisensory object discrimination. Brain Research. Cognitive Brain Research, 24(2), 326-334.

Lezak, M. (1995). Neuropsychological assessment. New York: Oxford University Press.

Li, H., Shu, H., McBride-Chang, C., Liu, H. Y., \& Xue, J. (2009). Paired associate learning in Chinese children with dyslexia. Journal of Experimental Child Psychology, 103(2), 135-151.

Linder, M., \& Grissemann, H. (2000). Zürcher Lesetest. Bern-Göttingen: Hogrefe-Verlag.

Livingstone, M., \& Hubel, D. (1988). Segregation of form, color, movement, and depth: Anatomy, physiology, and perception. Science, 240(4853), 740-749.

Lovegrove, W. J., Bowling, A., Badcock, D., \& Blackwood, M. (1980). Specific reading disability: Differences in contrast sensitivity as a function of spatial frequency. Science, 210(4468), 439-440.

Lux, S., Helmstaedter, C., \& Elger, C. E. (1999). Normative study on the "Verbaler Lern- und Merkfahigkeitstest" (VLMT): Diagnostica.

Lyon, G., Shaywitz, S., \& Shaywitz, B. (2003). A definition of dyslexia. Annals of Dyslexia, 53, 1-14.

Messbauer, V. C., \& de Jong, P. F. (2003). Word, nonword, and visual paired associate learning in Dutch dyslexic children. Journal of Experimental Child Psychology, 84(2), 77-96.

Miller, P., \& Kupfermann, A. (2009). The role of visual and phonological representations in the processing of written words by readers with diagnosed dyslexia: Evidence from a working memory task. Annals of Dyslexia, 59(1), 12-33.

Muter, V., Hulme, C., Snowling, M. J., \& Stevenson, J. (2004). Phonemes, rimes, vocabulary, and grammatical skills as foundations of early reading development: Evidence from a longitudinal study. Developmental Psychology, 40(5), 665-681.

Newell, A., \& Rosenbloom, P. S. (1981). Mechanisms of skill acquisition and the law of practice. In J. R. Anderson (Ed.), Cognitive skills and their acquistion (pp. 1-55). Hillsdale: Lawrence Erlbaum Associates.

Nicolson, R. I., \& Fawcett, A. J. (1990). Automaticity: A new framework for dyslexia research? Cognition, 35(2), 159-182.

Nyberg, L., Habib, R., McIntosh, A. R., \& Tulving, E. (2000). Reactivation of encoding-related brain activity during memory retrieval. Proceedings of the National Academy of Sciences of the United States of America, 97(20), 11120-11124.

Paulesu, E., Frith, U., Snowling, M., Gallagher, A., Morton, J., Frackowiak, R. S., et al. (1996). Is developmental dyslexia a disconnection syndrome? Evidence from PET scanning. Brain, 119(Pt 1), 143-157.

Posner, M. I., \& Presti, D. (1987). Selective attention and cognitive control. Trends in Neurosciences, 10, $12-17$.

Posner, M. I., \& Rafal, R. D. (1987). Cognitive theories of attention and the rehabilitation of attentional deficits. In R. J. Meier, A. C. Benton, \& L. Diller (Eds.), Neuropsychological rehabilitation. Edinburgh: Churchill Livingstone.

R Development Core Team. (2005). A Language and Environment for Statistical Computing. R Foundation for Statistical Computing. Vienna, Austria: ISBN 3-900051-07-0.

Ramus, F., Rosen, S., Dakin, S. C., Day, B. L., Castellote, J. M., White, S., et al. (2003). Theories of developmental dyslexia: Insights from a multiple case study of dyslexic adults. Brain, 126(4), 841-865.

Re, A. M., Caeran, M., \& Cornoldi, C. (2008). Improving expressive writing skills of children rated for ADHD symptoms. Journal of Learning Disabilities, 41(6), 535-544.

Reed, M. A. (1989). Speech perception and the discrimination of brief auditory cues in reading disabled children. Journal of Experimental Child Psychology, 48(2), 270-292.

Rudel, R. G. (1985). The definition of dyslexia: Language and motor deficits. In F. H. Duffy \& H. Gschwind (Eds.), Dyslexia: A neuroscientific approach to clinical evaluation (pp. 33-53). Boston: Little Brown.

Schulte-Korne, G., Deimel, W., Bartling, J., \& Remschmidt, H. (2004). Neurophysiological correlates of word recognition in dyslexia. Journal of Neural Transmission, 111(7), 971-984.

Shams, L., \& Seitz, A. R. (2008). Benefits of multisensory learning. Trends in Cognitive Sciences, 12(11), $411-417$.

Snowling, M., Bishop, D. V., \& Stothard, S. E. (2000). Is preschool language impairment a risk factor for dyslexia in adolescence? Journal of Child Psychology and Psychiatry, 41(5), 587-600.

Stein, J., \& Walsh, V. (1997). To see but not to read; the magnocellular theory of dyslexia. Trends in Neurosciences, 20(4), 147-152. 
Steingruber, H. J. (1971). Hand-Dominanz-Test (HDT). Göttingen: Verlag für Psychologie Dr. C. J. Hogrefe. Tallal, P. (1980). Auditory temporal perception, phonics, and reading disabilities in children. Brain and Language, 9(2), 182-198.

Tewes, U., \& Rossmann, P. U. S. (1999). Hamburg-Wechsler-Intelligenztest für Kinder. Bern: Verlag Hans-Huber. van Atteveldt, N. M., Formisano, E., Goebel, R., \& Blomert, L. (2007). Top-down task effects overrule automatic multisensory responses to letter-sound pairs in auditory association cortex. Neuroimage, 36(4), 1345-1360.

Vellutino, F. R., Fletcher, J. M., Snowling, M. J., \& Scanlon, D. M. (2004). Specific reading disability (dyslexia): What have we learned in the past four decades? Journal of Child Psychology and Psychiatry, $45(1), 2-40$.

Vellutino, F. R., Steger, J. A., Harding, C. J., \& Phillips, F. (1975). Verbal vs non-verbal paired-associates learning in poor and normal readers. Neuropsychologia, 13(1), 75-82.

Wheeler, M. E., Petersen, S. E., \& Buckner, R. L. (2000). Memory's echo: Vivid remembering reactivates sensory-specific cortex. Proceedings of the National Academy of Sciences of the United States of America, 97(20), 11125-11129.

Wolff, P. H., Michel, G. F., \& Ovrut, M. (1990). Rate variables and automatized naming in developmental dyslexia. Brain and Language, 39(4), 556-575.

World Health Organization. (1993). ICD-10. The international classification of diseases. Geneva: World Health Organization.

Zimmermann, P., Gondan, M., \& Fimm, B. (2002). KITAP Testbatterie zur Aufmerksamkeitsprüfung für Kinder. Herzogenrath: Psytest, Vera Fimm, Psychologisches Testsysteme. 